\title{
Resumos dos Trabalhos de Conclusão de Curso Bacharelado em Teologia - Turma 2017
}

\section{AUTORIA}

Álvaro Emanoel da Silva - Pesquisador

Prof. Msc. Celso Loraschi - Orientador

\section{TÍTULO}

A COMUNIDADE JUDAICO-CRISTÃ DO EVANGELHO DE MATEUS

\section{RESUMO}

A comunidade do Evangelho de Mateus era formada, em grande parte, por cristãos de origem judaica. Entre os fatores que levaram a redação do evangelho podemos destacar a instituição de uma assembleia judaica forte no pós-exílio para manter a integridade do judaísmo formativo; a dominação da cultura grega e a destruição de Jerusalém por parte do Império Romano. O povo de Israel tenta resistir a todos esses desafios com uma instituição e uma lei relativamente fortes, dando assim maior solidez às assembleias judaicas. Jesus de Nazaré insere-se neste contexto e é apresentado no Evangelho de Mateus como um judeu de seu tempo. Surge uma nova comunidade formada a partir do Evangelho de Mateus como um resgate das antigas assembleias judaicas, desta vez com algo novo: Jesus de Nazaré.

\section{Palavras-chave:}

Judaísmo formativo. Jesus histórico. Evangelho de Mateus.

\section{OBJETIVOS}

- Analisar o judaísmo do primeiro século e os fatores que influenciaram a formação da comunidade de Mateus;

- Entender Jesus de Nazaré como um judeu de seu tempo, sua formação judaica e os anos escondidos em Nazaré; 
- Perceber a influência da cultura greco-romana para o Evangelho de Mateus;

- Analisar alguns textos do Evangelho de Mateus que nos mostram as principais raízes do judaísmo do primeiro século.

\section{PRINCIPAIS REFERÊNCIAS}

GALLAZZI, Sandro. O Evangelho de Mateus: Uma leitura a partir dos pequeninos. São Paulo: Fonte Editorial. Aparecida: Editora Santuário. 2013.

OROFINO, Francisco. Hermenêutica bíblica a partir do Evangelho de Mateus: Transcrições das palestras proferidas pelo assessor Francisco Orofino. In Tríduo Bíblico 26 a 28 de maio de 2014. Faculdade Católica de Santa Catarina: Cadernos Bíblicos 02.

SALDARINI, Anthony J. A comunidade judaico-cristã de Mateus. São Paulo: Paulinas, 2000.

$* * *$

\section{AUTORIA}

André Schtck Petermann - Pesquisador

Prof. Msc. Adalberto Donadelli Junior - Orientador

\section{TÍTULO}

\section{A FORMAÇÃO INTEGRAL DO PRESBÍTERO HOJE PARA UMA VIDA DE COMUNHÃO}

\section{RESUMO}

Neste estuda-se um percurso formativo que possibilite uma formação integral do presbítero hoje para uma vida em comunhão; por meio de pesquisas de cunho teórico-bibliográfico, de caráter histórico e documental na área de conhecimento da teologia, tendo como subárea a formação presbiteral. Utiliza-se em especial os recursos eclesial-bibliográficos: decretos, exortações, constituições, diretórios, diretrizes, entre outros; bem como, a teologia dos Santos Padres sobre o sacerdócio; também, mencionam-se autores contemporâneos. Aborda-se de forma especial o ministério presbiteral, sua natureza, sua identidade, sua vida e missão, bem como, seus fundamentos; para contextualizar a formação presbiteral em si, com seus desafios e com suas contribuições para uma forma- 
ção integral em perspectivas de comunhão. Traça-se por fim um estereótipo do ser padre hoje a partir das dimensões formativas e culmina-se na definição de um ser "em", “de" e "para” a comunhão.

\section{Palavras-chave:}

Formação Presbiteral. Formação Integral. Comunhão.

\section{OBJETIVOS}

- Apresentar um percurso formativo que possibilite a integralidade formativa do presbítero hoje para uma vida em comunhão.

- Identificar o ministério presbiteral nos dias atuais.

- Demonstrar o processo de formação presbiteral hoje e seus desafios.

- Elaborar uma proposta de formação integral para uma vida em comunhão.

\section{PRINCIPAIS REFERÊNCIAS}

CENCINI, Amadeo. Fraternidade a caminho: rumo à alteridade. Trad. José Afonso Beraldin. São Paulo: Paulinas, 2003.

CONFERÊNCIA GERAL DO EPISCOPADO LATINO-AMERICANO E DO CARIBE V, 2007, Aparecida. Documento de Aparecida: texto conclusivo. 2. ed. Brasília: CNBB, 2007. CONFERÊNCIA NACIONAL DOS BIPOS DO BRASIL. Diretrizes para a Formação dos Presbíteros da Igreja no Brasil. 2. ed. São Paulo: Paulinas, 2011. (Documento 93).

CONGREGAÇÃO PARA O CLERO. Diretório para o ministério e a vida dos presbíteros. São Paulo: Paulinas, 2013.

VIANA, Wellistony Carvalho. Um longo e belo caminho: Um itinerário para seminaristas. Brasília: CNBB, 2013.

$$
* * *
$$

\section{AUTORIA}

Edson De Bortoli - Pesquisador

Dr. Vitor Galdino Feller - Orientador 


\section{TÍTULO}

PEQUENAS COMUNIDADES: A RENOVAÇÃO PASTORAL NA ESTRUTURA COMUNITÁRIA COMO CAMINHO PARA O DESENVOLVIMENTO DA INICIAÇÃO À VIDA CRISTÃ

\section{RESUMO}

Este trabalho, realizado por meio de pesquisa bibliográfica e de pesquisa de campo, apresenta as pequenas comunidades como configuração eclesial a ser priorizada para que aconteça uma renovação da dimensão comunitária da Igreja. Tal modelo torna possível o processo de iniciação à vida cristã com inspiração catecumenal. A iniciação à vida cristã necessariamente acontece no seio de uma comunidade eclesial. Porém, atualmente se constata uma realidade de crise na dimensão comunitária da Igreja, crise esta que precisa ser superada, ou ao menos amenizada, caso se pretenda efetivar o processo de iniciação à vida cristã. Inspirando-se na estratégia paulina de evangelização, fundamentando-se em documentos eclesiais e tendo por base os dados obtidos a partir da realização de uma pesquisa de campo, este trabalho defende que priorizar a estrutura eclesial das pequenas comunidades é uma ação capaz de levar a uma renovação na dimensão comunitária da Igreja. As pequenas comunidades favorecem o sentimento de pertença, a participação, a acolhida, a integração e o comprometimento entre os seus membros. Estes elementos são fundamentais em uma comunidade que faça o processo de iniciação à vida cristã com inspiração catecumenal.

\section{Palavras-chave:}

Iniciação à vida cristã. Comunidade. Igreja.

\section{OBJETIVOS}

- Identificar os aspectos que fazem com que a comunidade seja elemento constitutivo do processo de iniciação à vida cristã com inspiração catecumenal.

- Avaliar a condição da dimensão comunitária na presente realidade eclesial.

- Apresentar o modelo das pequenas comunidades como paradigma que possibilita o processo de iniciação à vida cristã. 


\section{PRINCIPAIS REFERÊNCIAS}

CONFERÊNCIA NACIONAL DOS BISPOS DO BRASIL. Comunidade de comunidades: uma nova paróquia: a conversão pastoral da paróquia. CNBB: 2014 (Documento 100).

NENTWIG, Roberto. Iniciação à comunidade cristã: a relação entre a comunidade evangelizadora e o catecumenato de adultos. São Paulo: Paulinas, 2013. (Coleção catequética).

REINERT, João F. Paróquia e iniciação cristã: a interdependência entre renovação paroquial e mistagogia catecumenal. São Paulo: Paulus, 2015.

\section{$* * *$}

\section{AUTORIA}

Eliton Fernando Felczak - Pesquisador

Msc. Celso Loraschi - Orientador

\section{TÍTULO}

A ESPIRITUALIDADE CRISTÃ COMO ITINERÁRIO DE AMADURECIMENTO HUMANO SEGUNDO ANSELM GRÜN

\section{RESUMO}

O estudo refere-se à argumentação da espiritualidade cristã como itinerário de amadurecimento humano segundo Anselm Grün. Tem como objeto a espiritualidade cristã na perspectiva antropológica da humanização das pessoas. A pesquisa tem sua relevância no campo das ciências humanas e da antropologia, pois a dimensão espiritual no mundo contemporâneo tem sido deixada de lado ou até mesmo igonrada. Com a presente pesquisa, traz-se a questão antropológica da espiritualidade ao primeiro plano nos debates acerca da valorização e da humanização da vida.

\section{Palavras-chave:}

Anselm Grün. Espiritualidade. Humanização. Amadurecimento.

\section{OBJETIVOS}

- Propor a espiritualidade cristã como itinerário de amadurecimento humano segundo Anselm Grün. 
- Colocar o que é primordial na espiritualidade cristã.

- Tratar da identidade da espiritualidade cristã.

- Abordar o desenvolvimento da condição humana com base na vida espiritual.

\section{PRINCIPAIS REFERÊNCIAS}

BOFF, Leonardo. Espiritualidade: um caminho de transformação. Rio de Janeiro: Sextante, 2006.

GRÜN, Anselm. Bíblia: reflexões e meditações. Petrópolis, RJ: Vozes, 2008.

GRÜN, Anselm. Espiritualidade e entusiasmo. São Paulo: Paulinas, 2008.

GRÜN, Anselm. Fontes da força interior. Evitar o esgotamento, aproveitar as energias positivas. Petrópolis, RJ: Vozes, 2007.

GRÜN, Anselm. Mística: descobrir o espaço interior. Petrópolis, RJ: Vozes, 2012.

GRÜN, Anselm. Os Padres do deserto: temas e textos. Petrópolis, RJ: Vozes, 2009.

GRÜN, Anselm; DUFNER, Meinrad. Espiritualidade a partir de si mesmo. Petrópolis, RJ: Vozes, 2004.

GRÜN, Anselm; MÜLLER, Wunibald. Deus, quem és Tu? Petrópolis, RJ: Vozes, 2012.

$$
* * *
$$

\section{AUTORIA}

Guilherme dos Santos - Pesquisador

Dr. Rafael Aléx Lima da Silva - Orientador

\section{TÍTULO}

\section{O SENTIDO ESPIRITUAL DAS MÃOS NA CELEBRAÇÃO EUCARÍSTICA}

\section{RESUMO}

Como propor uma espiritualidade para a contemporaneidade a partir da gestualidade das mãos na Celebração Eucarística? Inspiramo-nos nos textos da Sagrada Escritura, no testemunho dos Padres, nos livros litúrgicos, somados ao apoio da ciência litúrgi- 
ca. Partindo daí, procuramos apresentar a relação entre liturgia e espiritualidade e seu enraizamento no mistério de Cristo. Explicitamos isso com um exercício prático do caminho mistagógico a partir da gestualidade das mãos na celebração eucarística. Por fim, apresentamos alguns acenos de ars celebrandi para melhorar a comunicação do mistério nas comunidades.

\section{Palavras-chave:}

Liturgia. Gestualidade. Mistagogia. Espiritualidade litúrgica.

\section{OBJETIVOS}

- Apontar a gestualidade das mãos no rito eucarístico enquanto fonte de espiritualidade para o ser humano contemporâneo.

- Analisar a gestualidade das mãos no rito da Celebração Eucarística.

- Compor uma proposta de espiritualidade litúrgica para o ser humano contemporâneo a partir do conteúdo estudado.

- Propor elementos de gestualidade das mãos para uma melhor transmissão da mensagem de cada momento ritual.

\section{PRINCIPAIS REFERÊNCIAS}

CORDEIRO, José de Leão (Org.). Antologia litúrgica: textos litúrgicos, Patrísticos e canônicos do primeiro milênio. 2 ed. Fátima: Secretariado Nacional de Liturgia, 2015.

BÍBLIA de Jerusalém. São Paulo: Paulus, 2012.

BOSELLI, Goffredo. O sentido espiritual da liturgia. Brasília: CNBB, 2014.

CASTELLANO, Jesus C. Liturgia e vida espiritual: teologia, celebração, experiência. São Paulo: Paulinas, 2008.

CONGREGAÇÃO PARA O CULTO DIVINO E DISCIPLINA DOS SACRAMENTOS. Missal Romano. 10 ed. São Paulo: Paulus, 2006.

\section{$* * *$}

\section{AUTORIA}

Ismael Weiduschath - Pesquisador

Dr. Vitor Galdino Feller - Orientador 


\section{TÍTULO}

\section{A RESSURREIÇÃO COMO EVENTO ESCATOLÓGICO SE- GUNDO JÜRGEN MOLTMANN}

\section{RESUMO}

O presente trabalho de conclusão de curso, de cunho teórico-bibliográfico, debruça-se sobre o significado da ressurreição como evento escatológico segundo Jürgen Moltmann. Para o desenvolvimento desta pesquisa, este trabalho embasa-se, principalmente, nas obras Teologia da Esperança, O caminho de Jesus Cristo e $O$ Deus crucificado. Em primeiro lugar, de forma breve, apresentar-se-á a noção bíblica de ressurreição, considerando algumas das contribuições exegético-teológicas de Moltmann. Em seguida, apresentar-se-á a escatologia na perspectiva moltmanniana, evidenciando o lugar central da escatologia na reflexão teológica. Por fim, evidenciar-se-á a relação entre escatologia e ressurreição, tendo como intuito responder à problemática central deste trabalho. Para Moltmann, a ressurreição de Jesus não se reduz ao acontecimento testemunhado pelos discípulos, mas abarca e supera toda a história. A afirmação de fé na ressurreição como evento escatológico permite aos cristãos de todos os tempos fazer a experiência com o Cristo ressuscitado que continua presente e atuante na história.

\section{Palavras-chave:}

Ressurreição. Escatologia. Jürgen Moltmann.

\section{OBJETIVOS}

- Aprofundar o significado teológico da ressurreição como evento escatológico à luz do pensamento de Moltmann.

- Apresentar a ressurreição na perspectiva bíblica.

- Conceituar a escatologia no pensamento de Moltmann.

- Identificar o significado de ressurreição como evento escatológico segundo Moltmann.

\section{PRINCIPAIS REFERÊNCIAS}

MOLTMANN, J. Teologia da Esperança: estudos sobre os fundamentos e as consequências de uma escatologia cristã. Tradução de Helmuth Alfredo Simon. São Paulo: Herder, 1971. 
. O caminho de Jesus Cristo: cristologia em dimensões messiânicas. Tradução de Ilson Kayser. São Paulo: Academia Cristã, 2009.

. O Deus crucificado: a cruz de Cristo como base e crítica da teologia cristã. Tradução de Juliano Borges de Melo. Santo André: Academia Cristã, 2014.

$$
* * *
$$

\section{AUTORIA}

José Maria Monteiro de Sousa Filho - Pesquisador

Dr. Vilmar Adelino Vicente - Orientador

\section{TÍTULO}

RELIGIOSIDADE POPULAR: CONVERGÊNCIAS E DIVERGÊNCIAS NO CASO DO PE. CÍCERO ROMÃO BATISTA.

\section{RESUMO}

Esta pesquisa de bacharelado acadêmico busca analisar a vivência da fé da Católica em âmbito oficial e popular, os aspectos históricos que originaram uma prática mais erudita e outra popular da mesma fé. O que essas vivências convergem e divergem, percorrendo os documentos da Igreja e das Conferências Episcopais Latino Americanas e do Caribe, tendo como enfoque o caso singular do Pe. Cícero Romão Batista em Juazeiro do Norte - CE.

\section{Palavras-chave:}

Religiosidade popular. Devoção. Fé.

\section{OBJETIVOS}

- Analisar a realidade da Igreja Católica oficial com relação à religiosidade popular no Brasil, com enfoque na região nordeste no caso do Padre Cícero Romão Batista, em Juazeiro do Norte - CE; no que essas experiências convergem ou divergem, na tentativa de valorizar a riqueza da coexistência de ambas, que perpassam a vida das pessoas.

- Promover um levantamento histórico bibliográfico sobre a religiosidade popular e religião oficial, tendo como recorte o caso do Pe. Cícero Romão Batista. 
- Analisar as convergências e divergências de ambas.

- Demonstrar à luz do Magistério o valor e a importância de ambas.

\section{PRINCIPAIS REFERÊNCIAS}

COMBLIN, José. Padre Cícero de Juazeiro. São Paulo: Paulus, 2011. (Col. Biografias).

IRARRÁZAVAL, Diego In: Catolicismo Popular, história, cultura, teologia. Petrópolis - RJ: Vozes, 1992 (Desafios da religião do povo).

OLIVEIRA, Pedro A. Ribeiro. Religião e dominação de classe: gênese, estrutura e função do catolicismo romanizado no Brasil. Petrópolis: Vozes 1985.

VILHENA, Maria Angela. A religiosidade popular à luz do Concílio Vaticano II. São Paulo: Paulus, 2015.

$$
* * *
$$

\section{AUTORIA}

Marcelo Marques de Oliveira - Pesquisador

Me. Raphael Novaresi Leopoldo - Orientador

\section{TÍTULO}

QUAERERE DEUM: A ESTUDIOSIDADE COMO UM CAMINHO QUE CONDUZ A DEUS.

\section{RESUMO}

Esta pesquisa busca apresentar o horizonte da estudiosidade como um caminho que conduz a Deus. A relevância do tema se dá pelo fato de a estudiosidade ser uma virtude essencial para o teólogo que consagra sua vida ao trabalho intelectual e à procura de Deus. De ordem bibliográfica, a pesquisa é feita no campo do Método Teológico, tendo por base a obra: A vida intelectual: seu espírito, suas condições, seus métodos (1944), de AntoninDalmace Sertillagens, também serão tomadas por referências as obras: Introdução à vida intelectual (2001), de João Batista Libanio e Didascalicon: a arte de ler (1117), de Hugo de São Vitor. A reflexão busca encorajar e dar bases e orientações para o intelectual 
cristão que consagra a sua vida a tão nobre ideal: o de procurar e achar o tesouro da verdade. Encontrar a verdade é difícil, e o caminho é acidentado. Como buscador da verdade, um intelectual cristão deve investigar e questionar criticamente as fontes e fatos por todos os lados e não acreditar cegamente no que uma pessoa ou grupo diz é uma atitude sábia. Como buscador da verdade, o intelectual consagrado deve questionar e suspeitar de todas as suas ideias ao investigar os fatos, evitando com isso os preconceitos ou pensamentos descuidados.

\section{Palavras-chave:}

Estudiosidade. Deus. Verdade.

\section{OBJETIVOS}

- Apresentar a estudiosidade como um caminho que conduz a Deus..

- Descrever algumas noções de estudiosidade.

- Investigar algumas condições necessárias para a estudiosidade.

- Expor possibilidades e frutos.

\section{PRINCIPAIS REFERÊNCIAS}

LIBANIO, João B. Introdução à vida intelectual. 3. ed. São Paulo: Loyola, 2006.

SERTILLANGES, Antonin D. A vida intelectual: seu espírito, suas condições, seus métodos. Trad. Lilia L. da Silva. São Paulo: É Realizações, 2010.

VITOR, Hugo de S. Didascalicon: a arte de ler. Trad. Tiago Tondinalli. Campinas: Vide Editorial, 2015.

$$
* * *
$$

\section{AUTORIA}

Nicácio Alesso Aiello - Pesquisador

Vilmar Dal Bó Maccari - Orientador

\section{TÍTULO}

GESTÃO ECLESIAL: UM ESTUDO DE CASO SOBRE A REESTRUTURAÇÃO DA PASTORAL DO DÍZIMO NA PARÓQUIA SANTO ANTÔNIO E SANTA MARIA GORETTI 


\section{RESUMO}

Esta pesquisa tem por objetivo apresentar o projeto de reestruturação da Pastoral do Dízimo na Paróquia Santo Antônio e Santa Maria Goretti, no Bairro Coloninha, em Florianópolis/SC. A gestão administrativa paroquial se constitui uma dificuldade na maioria das paróquias no Brasil, pois a captação de recursos, cuja fonte principal deveria se consolidar com o dízimo, não atende as necessidades financeiras de manutenção do patrimônio, bem como despesas com funcionários e investimentos eclesiais. O estudo apresenta os fundamentos bíblico-teológicos do dízimo, dando sustentação para a prática de vida comunitária, na qual a caridade, o bem comum e a solidariedade são experimentados. A Pastoral do Dízimo deve possuir formação suficiente para subsidiar seu trabalho junto ao povo de Deus, cumprindo seu papel na manutenção da comunidade religiosa. Considerando as dificuldades administrativas da Paróquia da Coloninha e as fundamentações bíblico-teológicas do dízimo, promoveu-se a reestruturação da Pastoral do Dízimo da Paróquia, atendendo ao previsto no Documento 106 da CNBB, com a formação dos membros, ampliação da equipe e envio dos "Missionários do Dízimo" cumprindo também o que prevê o Estatuto da Arquidiocese de Florianópolis. Os resultados da conscientização serão percebidos ao longo da caminhada com a sistematização e regularização dos recursos captados pelo dízimo. Todavia o bom gestor deve estar atento para equalizar as despesas com a receita, para não sobrecarregar os fiéis.

\section{Palavras-chave:}

Gestão. Dízimo. Pastoral.

\section{OBJETIVOS}

- Executar e analisar a reestruturação da Pastoral do Dízimo na paróquia Santo Antônio e Santa Maria Goretti, a partir da proposta de renovação da Pastoral do Dízimo da CNBB.

- Apresentar os fundamentos bíblico-teológicos do dízimo.

- Apresentar a proposta de renovação da Pastoral do Dízimo da CNBB.

- Fazer uma análise qualitativa do progresso desta reestruturação pastoral na paróquia. 


\section{PRINCIPAIS REFERÊNCIAS}

CONFERENCIA NACIONAL DOS BISPOS DO BRASIL. O Dízimo na comunidade de fé: orientações e propostas. Brasília: CNBB, 2016. (Doc. 106).

GASQUES, Jerônimo. Um pouco de farinha e azeite: Dízimo - experiência de confiança solidária. São Paulo: Paulus, 2001. PEREIRA, José Carlos. Captação de recursos na estrutura paroquial: sugestões, possibilidades e implicações. Petrópolis: Vozes, 2010.

$* * *$

\section{AUTORIA}

Paulo Henrique de Lira Santos - Pesquisador

Dr. Vitor Galdino Feller - Orientador

\section{TÍTULO}

MATRIMÔNIO, UMA INSTITUIÇÃO VÁLIDA? UMA REFLEXÃO A PARTIR DA EXORTAÇÃO APÓSTOLICA PÓS-SINODAL AMORIS LAETITIA DO PAPA FRANCISCO.

\section{RESUMO}

O presente trabalho científico, tendo em vista a conclusão do curso bacharelado em Teologia, tem como referência fundamental a Exortação Apostólica Amoris Laetitia, do Papa Francisco, publicada após o Sínodo das Famílias, que aconteceu entre os anos de 2014 a 2015. Esta pesquisa tem como objetivo geral apresentar o matrimônio como uma instituição necessária na atualidade, mesmo que muitos meios existentes na realidade hodierna da sociedade queiram apresentar e convencer as pessoas do contrário.

\section{Palavras-chave:}

Matrimônio. Amoris Laetitia. Papa Francisco.

\section{OBJETIVOS}

- Apresentar o matrimônio como uma instituição válida na atualidade.

- Expor os fundamentos históricos e teológicos do matrimônio. 
- Compreender as proposições do Papa Francisco sobre o matrimônio e a família.

- Identificar algumas repercussões a partir da Amoris Laetitia.

\section{PRINCIPAIS REFERÊNCIAS}

FLÓREZ, Gonzalo. Matrimônio e família. Trad. Antonio Efro Feltrin. São Paulo: Paulinas, 2008.

FRANCISCO. Exortação apostólica pós-sinodal Amoris Laetitia. 1. ed. Brasília: CNBB, 2016.

GOEDERT, Valter Maurício. Casamento: fidelidade na esperança. São Paulo: Paulinas, 2005.

KASPER, Walter. Teologia do Matrimônio Cristão. Trad. Sérgio José Schirato. São Paulo: Paulinas, 1993.

SESBOUÉ, Bernard. Os sinais da salvação: os sacramentos e a Igreja, Virgem Maria. v. 3. São Paulo: Loyola, 2005.

$$
* * *
$$

\section{AUTORIA}

Paulo Sergio Chaves - Pesquisador

Msc. Pe. Siro Manoel de Oliveira - Orientador

\section{TÍTULO}

VIRTUDES TEOLOGAIS E TEOLOGIA DOS SANTOS: FUNDAMENTOS PARA SANTIDADE

\section{RESUMO}

O fio condutor que perpassa a santidade evangélica, vivenciada pelos cristãos católicos, concretiza-se nas virtudes da fé, esperança e caridade, dentre as quais destaca-se a caridade. Para o Apóstolo Paulo, o centro da vida cristã ilumina-se na complementariedade entre essas três virtudes. Na realidade, elas são necessárias para compreender a existência cristã, já que elas remetem às duas grandes balizas do discípulo de Cristo, isto é: a sua relação com Deus e com o próximo. A vida do crente está orientada para a transcendência. No entanto, o cristianismo postula um vínculo necessário entre vida sobrenatural e realização concreta. Ora, a compreensão de Deus, enquanto totalmente Outro, constrói-se a 
partir do rosto do próximo, isto é, o 'outro imediato e palpável'. Portanto, é fundamental para a teologia cristã-católica ter sempre bem presente a importância das virtudes teologais e seu desenvolvimento na Igreja, bem como da teologia dos santos e sua acuidade para a espiritualidade hoje, visando auxiliar o pensamento teológico mediante uma autêntica compreensão da santidade cristã. Busca-se, assim, responder às inquietações dos tempos hodiernos a respeito da santidade não de maneira utópica e sim, com uma base bíblico-teológica sólida, através das virtudes teologais e pondo-as em prática, a partir da oração e ação na realidade e na transcendência, num mundo secularizado a exemplo dos santos.

\section{Palavras-chave:}

Teologia. Virtudes. Santidade. Igreja.

\section{OBJETIVOS}

- Relacionar as Virtudes Teologais e a Teologia dos Santos

- Compreender os preâmbulos bíblicos da Tríade paulina: fé, esperança e caridade;

- Conceituar a reflexão teológica da Tríade paulina na teologia cristã;

- Identificar na fé, esperança e caridade os pressupostos à Teologia dos Santos.

\section{PRINCIPAIS REFERÊNCIAS}

SÖDING, Thomas. A Tríade fé, esperança e amor em Paulo. São Paulo: Loyola, 2003.

TOMÁS DE AQUINO. Suma Teológica. Ed. 3. São Paulo: Loyola, 2015.

MARÍN, Antônio R. Ser ou não ser santo: eis a questão. São Paulo: Eclesiae, 2016.

LÈTHEL, François-Marie. Connaître l'amour du Christ qui surpasse toute connaissance: le Théologie des Sants. Venasque: Éditions du Carmel, 1989. 


\section{AUTORIA}

Philipe Valdenô Damazo - Pesquisador

Dr. Renatus Porath - Orientador

\section{TÍTULO}

MOVIMENTOS PARA UMA NOVA EVANGELIZAÇÃO: ANÁLISE ISAIÂNICA DA TEOLOGIA DA LIBERTAÇÃO E DA RENOVAÇÃO CARISMÁTICA CATÓLICA

\section{RESUMO}

Esta pesquisa pretende apresentar possíveis convergências teológico-pastorais entre os movimentos da Teologia da Libertação e da Renovação Carismática Católica. Para tanto, se utilizará dos conceitos de justiça, mais atrelado a fundamentação da Teologia da Libertação; e também do conceito de louvor, este mais presente nos grupos da Renovação Carismática Católica. Terá como problemática a seguinte pergunta: há entre a Teologia da Libertação e a Renovação Carismática Católica possibilidades de convergências teológico-pastorais? Para responder a essa questão se procederá do seguinte modo: para atingir o primeiro objetivo, contextualizar-se-á o mundo do século XX, bem como a presença da Igreja, desde o pontificado de Leão XIII até o Concílio Vaticano II. Para o segundo objetivo se fará uma análise dos conceitos de justiça e louvor a partir do Livro do Profeta Isaías. E para o terceiro objetivo, tentar-se-á uma síntese entre ambos os movimentos a partir dos conceitos isaiânicos, apontando convergências entre a Teologia da Libertação e a Renovação Carismática para uma proposta de nova evangelização. Será utilizado um método teórico-bibliográfico, a partir da utilização de diversos autores experts em suas áreas.

\section{Palavras-chave:}

Teologia da Libertação. Renovação Carismática. Justiça. Louvor. Nova Evangelização.

\section{OBJETIVOS}

- Contextualizar a Igreja no século XX, apresentando os movimentos da Teologia da Libertação e da Renovação Carismática Católica.

- Analisar os conceitos de justiça e louvor a partir do livro do profeta Isaías. 
- Sintetizar a partir dos conceitos isaiânicos ambos os movimentos apresentando-os como proposta para Nova Evangelização.

\section{PRINCIPAIS REFERÊNCIAS}

COSTA, Lourenço (Org.). Documentos do Concílio Vaticano II (1962-1965). 2. ed. São Paulo: Paulus, 2002.

GUTIÉRREZ, Gustavo. Teologia da libertação: perspectivas. Tradução Yvone Maria de Campos Teixeira da Silva e Marcos Marcionilo. São Paulo: Loyola, 2000.

MANSFIELD, Patty Gallagher (Org.) Como em um Novo Pentecostes: o surpreendente início da Renovação Carismática Católica. Tradução Sueli Tronco. Edição jubileu de ouro da RCC. Canas: RCCBRASIL, 2016.

SICRE, José Luis. A justiça social nos profetas. Tradução Carlos Felício da Silveira. São Paulo: Paulinas, 1990.

PASSOS, João Décio. Concílio Vaticano II: reflexões sobre um carisma em curso. São Paulo: Paulus, 2014.

\section{$* * *$}

\section{AUTORIA}

Samuel Colombo Pirola - Pesquisador

Msc. Vilmar Dal Bó Maccari - Orientador

\section{TÍTULO}

OS DESAFIOS DAADMINISTRAÇÃO ECLESIAL NO HORIZONTE DA GESTÃO PAROQUIAL

\section{RESUMO}

O objetivo desta pesquisa é demonstrar a importância da gestão eclesial em um âmbito paroquial nos dias atuais. Para que se chegue a tal objetivo, será apresentado o desenvolvimento histórico da administração, diferenciando-o nas áreas pública, privada, terceiro setor e eclesiástica. A partir desta última, entra-se no ambiente paroquial, dando-se destaque aos desafios encontrados por um pároco ou futuro pároco, e apresentando uma perspectiva do que pode ser feito para o bom andamento de uma paróquia na área administrativa. 


\section{Palavras-chave:}

Gestão. Administração. Eclesial. Paróquia.

\section{OBJETIVOS}

- Demonstrar a importância da gestão eclesial em um âmbito paroquial;

- Analisar como se desenvolveu historicamente a ciência da administração;

- Sintetizar a natureza da ciência da administração, com enfoque na administração eclesiástica;

- Apresentar os desafios da administração eclesiástica dentro de um âmbito paroquial para os dias hodiernos.

\section{PRINCIPAIS REFERÊNCIAS}

ANDRADE, Rui Otávio Bernardes de; AMBONI, Nério. Teoria geral da administração. Rio de Janeiro: Elsevier, 2011.

CHIAVENATO, Idalberto. Introdução a teoria geral da administração. Barueri: Manole, 2015.

CÓDIGO DE DIREITO CANÔNICO. 13.ed. São Paulo: Loyola, 2014.

HENRIQUE, Mons. Nereudo F.; PAIVA, Edivaldo C. Fundamentos da gestão eclesial: manual para a área administrativa das paróquias. Petrópolis: Vozes, 2012.

NOGUEIRA, Luiz R. Gestão administrativa e financeira eclesiástica. Petrópolis: Vozes, 2008.

PEREIRA, José C. Gestão eficaz: sugestões para a renovação paroquial. São Paulo: Paulus, 2014.

$* * *$

\section{AUTORIA}

Sérgio Luís Pedrotti - Pesquisador

Dr. Vítor Galdino Feller - Orientador

\section{TÍTULO}

UMA LEITURA CRISTOLÓGICA E ECLESIAL DAS CATEQUESES DE JOÃO PAULO II SOBRE O AMOR HUMANO 


\section{RESUMO}

Esta pesquisa pretende analisar as catequeses do papa João Paulo II sob o enfoque da cristologia, observando as interferências profundas e transformações estruturais que tornam o matrimônio, em nossos dias, um extenso campo de observação e pesquisa, considerado a partir de uma antropologia adequada, fundamento para a família. Para tanto, o trabalho aponta a trajetória da cooperação do homem e da mulher na obra do Criador e assinala o testemunho que a família é convidada a dar ao mundo. Esta análise visa dar alguns instrumentos com os quais se possam criar novos e adequados modelos de ação pastoral, numa renovação continuada da ação evangelizadora da família hoje.

\section{Palavras-chave:}

Família. Matrimônio. João Paulo II.

\section{OBJETIVOS}

- Contribuir na atualização da reflexão das catequeses sobre o amor humano, indicando caminhos de compreensão da pessoa de Jesus Cristo e seu seguimento através da mediação vida-matrimônio-família.

- Examinar as catequeses do assim chamado primeiro ciclo, que têm como referência o Princípio, reconhecido fundamento da origem e do significado da família humana.

- Identificar o Mistério de Cristo nos escritos do papa João Paulo II sobre a família, de modo a localizar importantes traços de cristologia nos textos das catequeses.

- Reafirmar as perspectivas teológicas sobre a teologia do matrimônio, com destaque para a compreensão contemporânea das ações pastorais da Igreja em favor da família.

\section{PRINCIPAIS REFERÊNCIAS}

JOÃO PAULO II. Homem e mulher o criou: catequeses sobre o amor humano. Bauru: Edusc, 2005.

PAREDES, José Cristo Rey García. O que Deus uniu. Lisboa: Paulus, 2008.

PETRINI, João Carlos; DIAS, Marcelo Couto. Família no debate cultural e político contemporâneo. 2 ed. São Paulo: Loyola, 2015. SCOLA, Ângelo. O mistério nupcial. Bauru: Edusc, 2003. 